\title{
IMAGINÁRIO, IMAGINAÇÃO E RELAÇÕES SOCIAIS: REFLEXÕES SOBRE A IMAGINAÇÃO COMO SISTEMA PSICOLÓGICO
}

Maria Nazaré da Cruz*

\begin{abstract}
RESUMO: Este texto discute a imaginaçáo como atividade psíquica complexa, caracterizada por Vigotski como um sistema psicológico de relaçóes interfuncionais, a partir de elaboraçóes realizadas por Angel Pino sobre o imaginário e sobre o conceito de funçóes psicológicas, entre outras. Tem como escopo os problemas, discutidos por ele no ensaio $A$ produção imaginária $e$ a formaçáo do sentido estético, da natureza da imagem, das relações entre imaginário, simbólico e realidade, e da função imaginária. Consideramos que a produção teórica de Pino, nesse campo, oferece contribuiçóes fundamentais para a compreensão da imaginação como sistema psicológico e de sua importância para o desenvolvimento das possibilidades humanas de autodeterminação e liberdade. Tais contribuiçóes levaram-nos a formular, ao final do texto, indagaçóes referentes ao lugar da imaginação na educação de nossas crianças e jovens.
\end{abstract}

Palavras-chave: Imaginação. Funções psicológicas. Sistema psicológico.

* Universidade Metodista de Piracicaba (Unimep), Faculdade de Ciências Humanas, Piracicaba, SP., Brasil. E-mail de contato: nazarecruz@bol.com.br 


\section{Imaginary, imagination and social relations: reflections on imagination as a psychological system}

ABSTRACT: The present article discusses imagination as a complex mental activity and a psychological system of interfunctional connections, in accordance with Vygotsky's definition, and addresses issues highlighted by Angel Pino in the essay Imaginary production and the formation of aesthetic sense. When stating his ideas about the imaginary and the psychological functions, Pino points out the problems of the nature of image and the imaginary function, emphasizing the relationship between the imaginary and symbolic processes, on the one hand, and reality, on the other. We believe that his theoretical production in this field provides fundamental contributions to the understanding of imagination as a psychological system and its importance for the development of human possibilities of self-determination and freedom. These contributions have led us to formulate questions regarding the place of imagination in the education of our children and youth.

Keywords: Imagination. Psychological functions. Psychological system.

O imaginário é o que define a condição humana do homem.

Angel Pino

\section{INTRODUÇÃO}

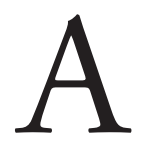

afirmação que serve de epígrafe a este texto encontra-se em um ensaio no qual Pino (2006, p. 47) discute a questão da "capacidade criadora do homem" e "o sentido estético de suas obras". Partindo do princípio de que o homem é produtor de suas condições de existência e tomando como referência para a compreensão de sua atividade a noção marxiana de trabalho social, o autor argumenta que o imaginário pode ser concebido como fonte de toda atividade produtiva humana, vez que esta, antes de se realizar concretamente, implica a criação como "processo da subjetividade restrita do sujeito produtor". 
Imaginário, nesse contexto, é concebido tanto como a capacidade criadora do homem quanto como o campo de suas produçóes imaginárias.

Para Pino, o imaginário - enquanto poder criador desenvolvido pela humanidade no decorrer da história - deve apresentar-se em cada um dos homens como processo subjetivo que antecede os seus atos de criação, de efetivação no plano do real ou do simbólico daquilo que havia sido produzido no campo do imaginário. Nesta direção, o campo do imaginário é um campo da subjetividade restrita, "ao qual só o sujeito tem acesso antes que seus conteúdos se tornem expressóes objetivas da subjetividade". (PINO, 2006, p. 54)

$\mathrm{Na}$ visão do autor, os termos imaginário e imaginação coincidem apenas parcialmente. Embora assuma sua preferência pela palavra imaginário, para referir-se ao poder criador do homem, Pino não chega a explicitar como concebe suas diferenças em relação ao termo imaginação, mais comum na tradição filosófica e psicológica (PINO, 2006, p. 54), inclusive na teoria de Vigotski ${ }^{1}$. As referências em que se assenta para assumir os sentidos que atribui ao imaginário são encontradas na obra de Cornelius Castoriadis, especialmente no conceito de imaginário radical.

Castoriadis $(1982 ; 1992)$ trata das questôes do imaginário em sua dimensão social-cultural - mas também aborda alguns aspectos de sua dimensão psicológica, subjetiva, individual como imaginação - e em suas relações com as instituiçôes e o simbólico, particularmente com a linguagem. A capacidade produtiva, criativa do imaginário consiste em sua principal característica. Para ele, a criação é compreendida como a disposiçáo de fazer surgir o que não estava dado e a imaginação como a capacidade de colocar novas formas, sendo ambas comuns a todos os homens.

Em seus escritos, Castoriadis $(1982 ; 1992)$ formula uma diferenciação entre o que denomina imaginário radical e o imaginário efetivo ou imaginado. O imaginário radical é compreendido como a capacidade de fazer aparecer como imagem alguma coisa que não é e não foi; como capacidade de ver em uma coisa o que ela não é, de vê-la diferente do que é; como faculdade originária de por ou dar-se, sob a forma de representação, uma coisa e uma relação que não são; como capacidade elementar e irredutível de evocar uma imagem. 
Sem desconhecer que a proposição de um imaginário que se confunde com o inconsciente freudiano precisa ser problematizada, particularmente quando se considera "[...] a visão do materialismo histórico e dialético, da qual Castoriadis parece estar próximo [...]" (PINO, 2006, p. 55), é em sua noção de imaginário radical que Pino encontra a possibilidade de pensar o imaginário como "uma fábrica de produção", como uma usina produtora de imagens.

Segundo Pino (PINO, 2006, p. 55), pode-se admitir com facilidade que as imagens são a "matéria-prima" da atividade imaginária, embora ainda saibamos muito pouco a respeito de sua natureza e dos processos de sua elaboraçáo, conservação e evocação. O problema da imagem e dos modos de compreendê-la suscita toda tensão inerente às visôes sobre o funcionamento imaginário, especialmente a tensáo entre reprodução da realidade e criação do novo. Retornaremos a esse ponto um pouco mais adiante neste texto.

Interessa-nos, antes, focalizar a concepção de Pino de que os problemas referentes à natureza e aos processos de produção da imagem estão relacionados, numa perspectiva vigotskiana, à noção de função imaginária. É precisamente aí que encontramos uma chave fundamental para problematizar nossa compreensão sobre o desenvolvimento da atividade imaginária na ontogênese e suas implicaçóes para a educação.

Em sua perspectiva, se pensarmos o imaginário como capacidade de criação do homem, podemos pressupor a existência de uma função específica - entre outras funçôes humanas como, por exemplo, a memória e a percepção: a função imaginária. Para o autor:

Falar da função imaginária apresenta alguns problemas que ainda não têm uma explicação satisfatória. Destaco dois deles: a natureza do material com que trabalha a função imaginária e a relação das produçôes imaginárias com o que denominamos real e simbólico. (PINO, 2006, p. 57)

São justamente esses problemas - da natureza da imagem, das relações entre imaginário, simbólico e realidade e da função imaginária - que nos interessam como escopo deste texto. Nosso propósito é 
discuti-los, entretecendo os argumentos apresentados no ensaio em questão (PINO, 2006) às elaboraçóes de Vigotski sobre a imaginação e seu desenvolvimento na ontogênese, de modo a contribuir para a elaboração da perspectiva vigotskiana sobre a imaginação, como atividade psíquica complexa que pode ser caracterizada como um sistema psicológico de relações interfuncionais (VIGOTSKI, 1998), e para a compreensão de suas implicaçôes para a formação e educação do homem.

Para tanto, tomaremos como base central de nossas reflexões, além do texto de Pino (2006) A produção imaginária e a formação do sentido estético, dois textos de Vigotski (1998; 1996), a saber: A imaginação e seu desenvolvimento na infância e Sobre os sistemas psicológicos. Outros trabalhos de Pino (2005; 2013), Vigotski (2000; 2011) e Castoriadis (1992) também comporão a discussão.

\section{AS RELAÇÕES ENTRE O REAL, O SIMBÓLICO E O IMAGINÁRIO}

O problema da natureza do material com que trabalha a função imaginária talvez só possa ser mais bem elaborado a partir de um melhor equacionamento da questão da relação das produçôes imaginárias com o que denominamos real e simbólico. Isto porque, conforme Pino (2006, p. 55) o "material básico" da atividade da imaginação são as imagens e, se a imagem é "uma espécie de reprodução da realidade" e as imagens humanas são de "natureza simbólica, detentoras de significação", a natureza da imagem também parece implicar as relaçôes entre produção imaginária, real e simbólico.

As relações entre a atividade imaginária e a realidade, tal como Vigotski as vê, são bem conhecidas entre aqueles que estudam sua obra. A primeira forma dessas relações é a de que toda criação imaginária parte de elementos tomados da realidade e resulta em uma modificação, uma reelaboração desses elementos. Outra forma é aquela em que imaginação possibilita o conhecimento do real a partir da experiência do outro, servindo como meio de ampliação da experiência do homem. É o que ocorre quando construímos imagens de lugares, fatos e coisas que nunca vimos. 
Um terceiro tipo de relação é aquele em que as imagens criadas pela fantasia são capazes de despertar emoçôes e sentimentos reais. Nesse caso, a imaginaçáo seleciona elementos da realidade e os combina, de modo que corresponda ao estado afetivo e não à lógica exterior. $\mathrm{O}$ produto da imaginação pode não coincidir com a realidade, mas é capaz de despertar emoçôes e sentimentos reais.

E, finalmente, o resultado da imaginação pode representar algo completamente novo, que ganha existência própria na realidade.

Esses produtos da imaginação passaram por uma longa história, que, talvez, deva ser breve e esquematicamente delineada. [...] Os elementos de que são construídos foram hauridos da realidade pela pessoa. Internamente, em seu pensamento, foram submetidos a uma complexa reelaboração, transformando-se em produto da imaginação. Finalmente, ao se encarnarem, retornam à realidade, mas já como uma nova força ativa que a modifica. Assim é o círculo completo da atividade criativa da imaginação. (VIGOTSKI, 2011, p. 28-29)

Vê-se, assim, que a atividade imaginária tanto toma do real a matéria sobre a qual opera, quanto produz novas (ir)realidades. Nesse contexto, é a possibilidade de recombinar fatos, impressôes, imagens já vividos que parece caracterizar a imaginação e sua capacidade criadora e, para Vigotski, é a imagem, como cópia mais ou menos fiel do real, que serve de base para essa atividade que combina e cria.

Mas, se é verdade que a imaginação baseia-se na experiência e na realidade, é também certo que o afastamento do real constitui-se movimento fundamental para o funcionamento imaginativo:

Para a imaginação é importante a direção da consciência, que consiste em afastar-se da realidade, em uma atividade relativamente autônoma da consciência, que se diferencia da cognição imediata da realidade. Junto com as imagens que se criam durante o processo de cognição imediata da realidade, o indivíduo 
cria imagens que são reconhecidas como produto da imaginação. [...] Toda penetração mais profunda na realidade exige uma atitude mais livre da consciência para com os elementos dessa realidade, um afastamento do aspecto externo aparente da realidade dada imediatamente na percepção primária. (VIGOTSKI, 1998, p.129)

Esta concepção dialeticamente manifesta uma ruptura com as marcas da imitação, da sensorialidade e da imagem como cópia, presentes no conceito de imaginação. Essa ruptura parece tornar-se possível pelo papel que Vigotski atribui à linguagem no desenvolvimento ontogenético da atividade da imaginaçáo. Para ele:

Com a ajuda da linguagem, a criança obtém a possibilidade de se libertar do poder das impressôes imediatas, extrapolando seus limites. A criança pode expressar com palavras também aquilo que não coincide com a combinação exata de objetos reais ou das correspondentes ideias. Isso lhe dá a possibilidade de se desenvolver com extraordinária liberdade na esfera das impressóes designadas mediante palavras. (VIGOTSKI, 1998, p.122)

Dito de outro modo, conforme argumenta Pino (2006, p. 55), o homem pode produzir imagens humanas “[...] transformando as imagens naturais em imagens de natureza simbólica, ou seja, detentoras de significação [...]" e é o caráter semiótico dessas imagens que possibilita a atividade criadora.

Nesse ponto, as relações entre real, imaginário e simbólico tornam-se bastante intrincadas, já que a própria linguagem, enquanto produção humana, implica a atividade criativa do imaginário. Ou seja, se o imaginário não prescinde do simbólico, este pressupõe necessariamente a capacidade imaginária, a capacidade de ver em uma coisa o que ela não é ou de vê-la diferente do que é. $\mathrm{O}$ imaginário, por sua vez, liga-se ao simbólico não somente para exprimir-se, mas para existir enquanto tal. (CASTORIADIS, 1992) 
Essas intrincadas relações, de múltiplas co-implicações entre real, simbólico e imaginário no funcionamento imaginativo, levam-nos a pensar, seguindo Vigotski (1998), na impossibilidade de se compreender a imaginação como uma função psíquica entre outras. Para ele, a imaginação deve ser compreendida como um sistema psicológico de natureza interfuncional. Passemos a esse ponto.

\section{IMAGINAÇÃO COMO SISTEMA PSICOLÓGICO}

Ao discutir o desenvolvimento da imaginação na infância, Vigotski (1998, p. 126) focaliza as relaçóes entre pensamento, emoções e imaginação, assumindo que, em diferentes atividades imaginativas, estabelecem-se relaçóes peculiares entre essas funçóes, sendo que em cada uma delas "nos encontramos diante de diferentes sistemas e diferentes gêneros de uma complicada atividade". Sendo assim, a imaginação poderia ser caracterizada como uma atividade psíquica complexa que implica a participação de "várias funçóes em suas peculiares relaçóes" (1998, p. 127), configurando o que se poderia chamar de um sistema psicológico.

Antes de tentarmos avançar a discussão sobre a ideia de sistemas psicológicos, tal como aparece na obra de Vigotski, parece pertinente nos indagarmos, seguindo Pino, sobre o sentido do termo "função" nesse contexto.

A maneira indefinida ou vaga como esse termo aparece nos escritos de Vygotski, paradoxalmente, abre a possibilidade de imaginar a "psique" humana - que segundo ele é um complexo de funçóes - como algo dinâmico e em contínuo movimento; algo que não se cristaliza em formas acabadas, mas que se constitui de maneira constante; algo que, falando em termos metafóricos, se situaria entre "a fumaça e o cristal", ou seja, entre a fluidez de uma e a fixidez do outro. Portanto, o termo funçáo remete muito mais à forma verbal de funcionar do que à forma substantiva de "função". (PINO, 2013, p. 92) 
No entanto, Pino (2005) reconhece, em diversos textos de Vigotski, o termo funçãa assumindo a significação de posição social, que remete ao exercício de papéis determinados, ou, ainda, de correspondência entre elementos de conjuntos distintos. Em sua concepção, esses dois sentidos podem ser articulados, vez que "[...] toda posição social é funçâo de outra posição que, opondo-se a ela e negando-a, a constitui [...]". (PINO, 2005, p.98)

Para Vigotski (1996, p. 113), “[...] toda função superior estava dividida entre duas pessoas, constituía um processo psicológico mútuo [...]", de modo que "[...] a relação entre as funções psicológicas superiores foi outrora relação real entre pessoas [...]". (VIGOTSKI, 2000, p. 25) Nesse contexto, a linguagem tem um papel central na formação das complexas conexóes psicológicas produzidas quando essas funções se transformam em individuais:

Todo signo, se tomarmos sua origem real, é um meio de comunicação e, poderíamos dizê-lo mais amplamente, um meio de conexão de certas funçôes psíquicas de caráter social. Trasladado por nós mesmos, é o próprio meio de união das funções em nós mesmos, e poderemos demonstrar que sem esse signo o cérebro e suas conexôes iniciais não poderiam se transformar nas complexas relaçóes, o que ocorre graças à linguagem. (VIGOTSKI, 1996, p. 114)

A noção de sistema psicológico, em Vigotski (1996), implica justamente a possibilidade constante de surgimento de novas, mutáveis e complexas relaçóes entre funçóes. Ele destaca que, durante o processo de desenvolvimento cultural, o que muda não são tanto as funçóes em si, mas principalmente as relaçóes entre elas, de modo que surgem novas possibilidades de funcionamento psíquico, inexistentes em momentos anteriores.

Sua análise do processo de desenvolvimento da imaginação contempla essas transformações das relações interfuncionais. No início do desenvolvimento da criança, quando ela começa a brincar de faz de conta, a situação imaginária que cria é ainda muito semelhante à 
situação real que ela representa, estando mais próxima da imitação e da memória que da criação. Com o desenvolvimento da linguagem e de seu papel na brincadeira, a criança passa, cada vez mais, a agir no campo das significaçóes, o que dará origem ao pensamento abstrato.

Assim, se na infância a atividade imaginária estabelece bases importantes para o pensamento racional, é apenas na adolescência que se produz uma estreita ligação entre a imaginação e a razão, duas forças que competem entre si e se entrelaçam. A imaginação desenvolve-se, adaptando-se a condiçốes racionais e vinculando-se ao pensamento conceitual.

Nesse contexto, Vigotski argumenta, apoiando-se em Jaensch, que a atividade psíquica da criança pequena é "eidética", já que sua memória, imaginação e pensamento tendem a reproduzir diretamente percepçóes reais, na sua integridade. No entanto, durante a transição do pensamento concreto para o pensamento abstrato e conceitual, as imagens eidéticas seriam transferidas para a esfera da imaginaçáo, mudando sua função psíquica básica. Nesse processo, a abstração é incorporada ao funcionamento imaginativo, levando a fantasia do adolescente a mover-se, por meio de um conceito, de uma imagem visual concreta para uma imagem imaginária, o que marca a transição de uma fantasia imitativa para uma fantasia criativa, produtiva.

Se retornarmos à questáo da natureza da imagem, a partir da inter-funcionalidade da imaginação, somos levados a pensar que, presumivelmente, os materiais sobre os quais ela opera não permaneçam invariáveis no curso do desenvolvimento ontogenético e/ou nas diferentes atividades imaginárias a que o sujeito se dedica. $\mathrm{O}$ caráter semiótico das imagens humanas, como argumenta Pino (2006), é indiscutível, mas sua natureza parece poder se aproximar ora da imagem eidética, ora do conceito verbal. Nessa direçáo, podemos perceber que, ao tratar o desenvolvimento da imaginação, Vigotski atribui maior amplitude e riqueza à atividade imaginária do adolescente e do adulto, em relaçáo à da criança. No entanto, ele também admite que a "curva da evolução da imaginação" possa entrar em declínio na vida adulta, perdendo espaço para as atividades cotidianas de reprodução da vida. Esse declínio, contudo, náo é sinônimo de desaparecimento: “[...] de fato, onde quer que 
se conserve uma ínfima parte da vida criativa, aí também tem lugar para a imaginação [...]”. (VIGOTSKI, 2011, p. 46)

Nesse ponto, um aspecto fundamental da análise de Vigotski (1996, p. 117) sobre os sistemas psicológicos precisa ser considerado, a saber, a concepção de que o papel que uma dada função representa em relação às outras, modifica-se histórica e culturalmente e tem sua origem no social. É por isso que ele afirma que os sistemas psíquicos conectam-se com a ideologia e que o significado que uma dada função adquire na consciência das pessoas, assim como as novas formas de comportamento que daí surgem, originam-se da ideologia do grupo social a que pertencem.

Nesse sentido, o que distingue os modos de agir dos homens tanto em diferentes tempos e contextos, quanto na mesma sociedade, não é o quanto cada função se desenvolveu em cada um deles, mas o papel que cada função desempenha no conjunto da vida psíquica. E essa diferença só pode ser explicada pela prática social dos homens, entendida por Pino (2005, p. 107) como “[...] as várias formas - socialmente instituídas ou consagradas pela tradição cultural dos povos - de pensar, de falar e de agir das pessoas que integram uma determinada formação social [...]", e pelas posiçóes que os sujeitos ocupam nela.

Sendo assim, para Vigotski (1996, p. 133), “[...] os traços sociais e de classe formam-se no homem a partir de sistemas interiorizados, que nada mais são do que sistemas e relaçóes sociais entre pessoas trasladados para a personalidade [...]". Disso se infere que os modos de participação da imaginação no funcionamento psíquico dependem do contexto social em que se dá o desenvolvimento ontogenético e das práticas sociais em que os sujeitos se inserem.

Vigotski (2011) reconhece que a distribuição das possibilidades de criação e de inovação é desproporcional entre as classes sociais, vez que as classes privilegiadas detêm melhores condiçóes para a criação. Se, à primeira vista, tal argumento pode parecer preconceituoso, podemos nele identificar, como aponta Smolka (2011, p. 41), “[...] o realce das condições concretas que podem viabilizar instâncias de criação, tornando possível a produção do novo [...]", o que, sem dúvida, possui implicações para a educação, especialmente se considerarmos que 
[...] as possibilidades de agir com liberdade, que surgem na consciência do homem, estão intimamente ligadas à imaginação, ou seja, à táo peculiar disposição da consciência para com a realidade, que surge graças à atividade da imaginaçáo [...]. (VIGOTSKI, 1998, p. 130)

\section{CONSIDERAÇÕES FINAIS}

Isto remete à epígrafe deste texto: "o imaginário é o que define a condiçẫo humana do homem" (PINO, 2006), na qual o qualificativo "humana", para o autor, vincula-se à possibilidade de autodeterminação, à liberdade e à consciência do homem.

Se essas possibilidades, assim como o próprio imaginário, estão presentes em cada um dos homens, podemos supor que, em um contexto de desigualdades sociais, o papel do imaginário/imaginação no funcionamento psíquico não é o mesmo em todos os homens.

Conforme já abordamos, Vigotski (1996) vê o psiquismo como um sistema de relaçóes interfuncionais, sempre mutável e inacabado. Para Pino (2005, p. 99), isto significa que as funçôes psíquicas não apenas se organizam à semelhança das relaçóes entre as pessoas, dando origem a conexóes interfuncionais, mas também que "[...] recompóem, no plano pessoal, as relaçóes de que participamos no plano social [...]”.

Esta visão nos conduz à concepção de Vigotski (2000) de que não é o pensamento que pensa, mas a pessoa. "Uma vez que a pessoa pensa, perguntamos: qual pessoa" e responder a isso parece implicar o conhecimento do contexto histórico-cultural, das relaçóes em que a pessoa está inserida e da posição que ocupa nelas. Reconhecer a concretude da pessoa que pensa é fundamental nesta perspectiva, já que “[...] com as mesmas leis do pensamento, o processo será diferente, dependendo de em qual pessoa ele acontece [...]". Dito de outro modo, as relaçóes interfuncionais serão diferentes. $\mathrm{O}$ papel do sonho, do pensamento, da imaginação, do afeto, da memória no funcionamento psíquico será distinto em cada pessoa e guardará as marcas de suas pertenças histórico-culturais. 
Sendo assim, podemos considerar que o declínio da "curva da evolução da imaginação", de que nos fala Vigotski, é produto de relações sociais determinadas. Considerando, como Castoriadis, a instituição social, pelo Ocidente, do pensamento como Razão, podemos atribuir aquele declínio à existência de processos sociais de disciplinamento da imaginação por meio de sua submissão à lógica racional ou, ainda, de queda ou anulação da fantasia que, nesse contexto, se oporia ao pensamento produtivo-instrumental sobre a realidade.

Diante desse quadro, torna-se imperativo formular algumas questóes, que nos parecem cruciais, referentes à educação de nossas crianças e jovens: como a atividade imaginária - que é uma atividade comum às crianças, na brincadeira, no desenho, nas suas narrativas, no interesse por contos e pelo fantástico etc. - tem sido trabalhada na educação infantil? Que papel tem sido atribuído à imaginação no processo escolar de elaboração do conhecimento sobre a realidade? Que possibilidades de acesso a condiçóes materiais e simbólicas de criação - nos campos da arte, da técnica e do conhecimento - têm sido oferecidas na formação escolar de nossas crianças, adolescentes e jovens?

Acreditamos que as respostas que historicamente pudermos construir para essas indagações terão enorme relevância para o engendramento (ou não) de possibilidades igualitárias de autodeterminação, liberdade e consciência para todos os homens.

\section{REFERÊNCIAS}

CASTORIADIS, C. A Instituição Imaginária da Sociedade. Rio de Janeiro, Paz e Terra, 1982. . A Criação Imaginária. Porto Alegre, Artes e Ofícios, 1992.

PINO, A. Natureza e cultura: as funções naturais na constituição do homem. In: SMOLKA, A. L. B.; NOGUEIRA, A. L. H. (Orgs.). Estudos na perspectiva de Vigotski: gênese e emergência das funçóes psicológicas. Campinas: Mercado da Letras, 2013, p. 71-98. 
PINO, A. A produção imaginária e a formação do sentido estético. Reflexôes úteis para uma educação humana. Pro-Posiçóes, Campinas, v. 17, n. 2(50), p. 47-69, ago. 2006.

. As marcas do humano: às origens da constituição cultural da criança na perspectiva de Lev S. Vigotski. São Paulo: Cortez, 2005.

SMOLKA, A. L. B. Apresentação e comentários. In: VIGOTSKI, L. S. Imaginação e criação na infância: ensaio psicológico: livro para professores. São Paulo: Ática, 2011.

VIGOTSKI, L. S. Imaginação e criaçâo na infância: ensaio psicológico. São Paulo: Ática, 2011. [Livro para professores].

. Manuscrito de 1929. Educ. Soc. Campinas, n. 71, p. 21-44, jul. 2000.

. A imaginação e seu desenvolvimento na infância. In: VIGOTSKI, L.

S. O desenvolvimento psicológico na infância. São Paulo: Martins Fontes, 1998, p. $107-130$.

. Sobre os sistemas psicológicos. In VIGOTSKI, L. S. Teoria e método em psicologia. São Paulo: Martins Fontes, 1996, p. 103-135.

\section{NOTAS}

1. Apurar conceitos e sentidos atribuídos aos termos que usamos para discutir questóes relativas à imaginação e ao imaginário tem se revelado uma tarefa de grande dificuldade, proporcional à complexidade da própria temática. Nesse contexto, sem pretender definir com precisáo e/ou fixar termos - o que, dada a natureza inicial de nossas reflexóes, certamente seria prematuro - vemo-nos diante da tarefa de esclarecer minimamente os sentidos que assumem neste texto. Sem desconsiderar a diferença apontada por Pino, quando estivermos nos referindo ao pensamento dos autores, empregaremos os termos que cada um deles utiliza, entendendo que imaginação, em Vigotski, pode incluir o sentido de imaginário e, ainda, aproximar-se das definições estabelecidas por Pino de função imaginária e de produção imaginária, no caso dessa última, atribuindo à produção não apenas o sentido de resultado, mas também de processo. Além disso, duas outras expressões aparecerão no decorrer do texto: atividade imaginária e funcionamento imaginativo. A primeira refere-se à atividade de criaçáo dos sujeitos; a segunda remete aos modos de funcionamento da imaginação enquanto processo psíquico.

Recebido em 15 de junho de 2015.

Aprovado em 30 de julho de 2015.

DOI: http://dx.doi.org/10.1590/CC0101-32622015V35ESPECIAL154116 